\title{
Performance Optimization of Modified Gussasphalt Binder Prepared Using Natural Asphalt
}

\author{
Tao $\mathrm{Li}^{1 \dagger}$, Qing Jin ${ }^{2 * t}$, Peng Jiang ${ }^{2 *}$, Huadong Sun ${ }^{3 *}$, Yongling Ding ${ }^{3 *}$, Zongyao Yan ${ }^{1}$ and \\ Nan Shi ${ }^{1}$ \\ ${ }^{1}$ Shandong Hi-speed Construction Management Group Co., Ltd., Jinan, China, ${ }^{2}$ School of Civil Engineering, Shandong \\ University, Jinan, China, ${ }^{3}$ School of Civil Engineering, Shandong Jiaotong University, Jinan, China
}

OPEN ACCESS

Edited by:

Han-Cheng Dan,

Central South University, China

Reviewed by:

Dongdong $\mathrm{Ge}$

Changsha University of Science and

Technology, China

Yuchao Lyu,

China University of Petroleum (East

China), China

*Correspondence:

Qing Jin

jinqing@sdu.edu.cn

Peng Jiang

jiangp2020@163.com

Huadong Sun

sunhuadong2004@163.com

Yongling Ding

204130@sdjtu.edu.cn

${ }^{\dagger}$ These authors have contributed equally to this work and share first

authorship

Specialty section:

This article was submitted to Structural Materials,

a section of the journal

Frontiers in Materials

Received: 21 December 2021

Accepted: 31 January 2022

Published: 28 February 2022

Citation:

$L i T$, Jin $Q$, Jiang $P$, Sun $H$, Ding $Y$, Yan $Z$ and Shi N (2022) Performance Optimization of Modified Gussasphalt

Binder Prepared Using

Natural Asphalt.

Front. Mater. 9:840380.

doi: $10.3389 /$ fmats.2022.840380
The advantageous thermal stability and construction workability of gussasphalt, a type of asphalt concrete, has drawn increasing attention. To prepare a type of superior gussasphalt concrete using Qingchuan rock asphalt (QRA), a modified gussasphalt binder was prepared with modifiers made up by different dose of styrene-butadienestyrene, terpene resin, furfural extraction oil and SAW. Then, the rheological properties, microstructure, and thermal stability of gussasphalt binder were studied. The results indicated that the modifier \#1 had significant effects on the other indexes but for the ductility, it was less effective in improving the low-temperature performance of the asphalt binder. The low-temperature performance of the binder with modifier \#2 was superior compared with that of binder with modifier \#1. The binder with 12.5\% QRA and 5\% modifier \#2 can be regarded as an optimal collocation, which had a superior compatibility, high-temperature performance, and comprehensive temperature susceptibility.

Keywords: gussasphalt, rock asphalt, rheological properties, compatibility, thermal stability

\section{INTRODUCTION}

Gussasphalt concrete presents a flowing state at an appropriate construction temperature $\left(220-250^{\circ} \mathrm{C}\right)$, which can autonomously reach the required density and flatness without compaction (Wang et al., 2011). Therefore, it is more suitable for bridge deck paving and other construction that heavy compaction machinery can't get involved. The overlay of bridge deck requires asphalt concrete with good durability, fatigue resistance, and water resistance (Pouget et al., 2010; Chen et al., 2011a; Gao et al., 2015; Jia et al., 2016). Some of steel box girder bridge exposed to sunlight could cause the overlay temperature to reach $70^{\circ} \mathrm{C}$ or higher, which shows the need for an overlay with good thermal stability (Chen et al., 2011a; Gao et al., 2015). Gussasphalt concrete not only meets these performance requirements, but can also effectively resist the stress caused by the partial deflection of the steel plate. It also possesses excellent adhesion and compliance with the steel deck (Qiu et al., 2019; Wang et al., 2019). Thus, gussasphalt concrete is suitable for deck paving, especially for long-span and medium-span steel bridges (Chen et al., 2011b; Sang Luo et al., 2018; Ke et al., 2019).

Numerous studies have been conducted on gussasphalt, which have made it possible to produce gussasphalt concrete with high quality. Wang and Li (2015), Liu (2019), and Zou et al. (2020) determined the effects of different factors like the gradation, preparation technique, and asphalt and modifier contents on the performance of gussasphalt and thereby obtained an optimum formula, which suggests the TLA content of $25-30 \%$. Xin et al. (2017) and Jin et al. (2014) analyzed the effects of different temperatures, asphalt types, and filler-asphalt ratios on the high-temperature properties using 
laboratory testing. The correlation between the performance of gussasphalt and its composition, and the relationship between the high-temperature deformation and generalized shear modulus, were explored. Zhang et al. (2010), Qian et al. (2013), and Wu et al. (2013) focused on the influences of different strain levels of loading on the fatigue performance of a gussasphalt mix. The fatigue resistance of the gussasphalt was analyzed and evaluated based on a four-point flexural fatigue test. By modifying the mechanical model of the Burgers model, Xie et al. (2017) and Luo R. et al. (2018) derived the viscoelastic material parameters using laboratory tests and theoretical equations. The pivotal factors leading to significant permanent deformation were discovered and summarized. With the progress of science and technology, additional functional research and development will help to improve the serviceability of basic transportation. A conductive gussasphalt (CGA) mix that can melt snow on a bridge deck is a good example of optimizing pavement rideability. Wang et al. (2018b) evaluated the ice melting efficiencies of CGA concrete prepared using various material combinations and studied the effects of the conductive material and asphalt concrete type on the engineering performance. Chen et al. (2019) systemically investigated the effects of the mix type, working conditions, and environmental factors of a CGA mix on the corrosion of a steel bridge deck. Wang et al. (2018a) proposed and evaluated a heat conduction estimation method and derived and verified a theoretical equation for a CGA combination structure. These studies revealed that CGA may have great potential applications in the field of steel deck overlays. However, Zhao et al. (2020) claimed that the gussasphalt applied on the Jiangyin Bridge had a weak high-temperature stability and a lower modulus (Bo Yao et al., 2013), according to an analysis of long-term maintenance data. Thus, there is an urgent need to optimize gussasphalt concrete to tolerate various application scenarios.

The mix proportion design of the gussasphalt binder is characterized by a high content of mineral powder and asphalt binder, high mixing temperature, and low coarse aggregate content. The asphalt binder plays the role of the skeleton, which is completely different from other asphalt concretes with coarse aggregates as the skeleton. The cohesion determines the strength of the gussasphalt concrete (Artamendi et al., 2017; Huang et al., 2019). The acquisition or improvement of each specific property of the asphalt binder can be realized through changes in its microstructure (Mazumder et al., 2018). The identification of the origin of the microstructure and chemical components associated with the formation of this microstructure can reveal the rheology (Yu et al., 2015; Das et al., 2016; Singh and Sawant, 2016). Physical properties such as the stiffness, elasticity, plasticity, adhesion, surface energy, and healing mainly depend on the microstructure of the asphalt (Grover Allen et al., 2014; Kim et al., 2017a). At present, most asphalt mix design methods adopt macroscopic parameters as the design indexes (Bo Yao et al., 2013; Wang and Li, 2015; Singh and Sawant, 2016; Shadkam et al., 2017; Zhang et al., 2018). However, many engineering practices have proved that the current design method cannot effectively control the material performance. In some cases, the statistical indicators are the same, but the performance varies greatly, which implies that some macroscopic design indicators do not conform to the material damage mode (Du, 2014; Cavalli et al., 2016; Kim et al., 2016; Yao and You, 2016). Understanding the properties of asphalt binders at the microscale may be beneficial for improving the knowledge of their macro-performance (Yang et al., 2020).

The use of different techniques to study the microstructure of asphalt is conducive to establishing the relationship between its microstructure and physical properties. Based on foundational laboratory tests, fluorescent microscope tests, and Superpave $\mathrm{T}^{\mathrm{TM}}$ tests, the compatibility of components at the microscale, thermal properties, and rheological properties of a composite natural asphalt modified gussasphalt (CNAMGA) binder were revealed. The optimal collocation of the CNAMGA binder was determined and verified.

\section{MATERIALS AND METHODS}

\subsection{Materials}

\subsubsection{Base Asphalt}

The base asphalt was 90\# Kunlun asphalt, and the relevant performance tests were conducted strictly according to Chinese standard E20-2011, Standard Test Methods of Bitumen and Bituminous Mixtures for Highway Engineering (Code of China, 2011). The results are listed in Table 1.

\subsubsection{Natural Asphalt}

In recent years, natural asphalt has been extensively studied and widely used in asphalt pavements. To explore more substitutes with high yield, stable properties, and low cost, Chinese Qingchuan rock asphalt (QRA) was employed for the preparation of gussasphalt in this study, according to T06142011 and T0618-1993 of Chinese standard E20-2011 (Code of China, 2011). The ash content of QRA was $4.5 \%$, asphalt aromatic was $31.49 \%$, saturate was $29.45 \%$, resin was $34.44 \%$ and asphaltene was $4.62 \%$.

\subsubsection{Modifying Agent}

Different modifying agents were adopted in this study (Table 2), it is widely acknowledged that Styrene-butadiene-styrene (SBS) can enhance the elasticity of binder at high temperatures and increase flexibility of binder at low temperatures, terpene resin (TR) is easy to mix with asphalt after heating and melting, and during this process, the initial adhesion and aging resistance of asphalt were greatly improved as well. Furfural extraction oil (FEO) can improve the elongation of asphalt at low temperature (Liu et al., 2018; Bai et al., 2019). It can be used as a blending component in asphalt to optimize the composition and make thermoplastic elastomers more compatible in asphalt. SAW modifier can reduce the high-temperature asphalt viscosity and the mixing temperature, and improve the hightemperature performance of asphalt mix.

\subsection{Test Method}

\subsubsection{Fluorescent Microscope}

The CNAMGA binder was heated to a flowing state, and a drop of the sample was taken with a needle and placed on a glass slide 
TABLE.1 | Technical indexes of 90\# base asphalt.

\begin{tabular}{|c|c|c|c|c|c|}
\hline Test index & & Unit & Specified value & Test results & Test method \\
\hline \multirow[t]{3}{*}{ Penetration } & $15^{\circ} \mathrm{C}, 100 \mathrm{~g}, 5 \mathrm{~s}$ & $0.1 \mathrm{~mm}$ & - & 40 & T0604 \\
\hline & $25^{\circ} \mathrm{C}, 100 \mathrm{~g}, 5 \mathrm{~s}$ & & $80-100$ & 92 & \\
\hline & $30^{\circ} \mathrm{C}, 100 \mathrm{~g}, 5 \mathrm{~s}$ & & - & 151 & \\
\hline Softening point ( $\mathrm{R}$ and $\mathrm{B})$ & & ${ }^{\circ} \mathrm{C}$ & $\geq 45$ & 50.5 & T0606 \\
\hline Ductility $\left(15^{\circ} \mathrm{C}, 5 \mathrm{~cm} / \mathrm{min}\right)$ & & $\mathrm{cm}$ & $\geq 100$ & 108 & T0605 \\
\hline Density $\left(25^{\circ} \mathrm{C}\right)$ & & $\mathrm{g} / \mathrm{cm}^{3}$ & Actual measurement & 1.109 & T0603 \\
\hline \multirow[t]{3}{*}{ Thin film oven test (TFOT) $\left(163^{\circ} \mathrm{C}, 300 \mathrm{~min}\right)$} & Mass loss & $\%$ & $-0.8-0.8$ & 0.04 & T0610 \\
\hline & Penetration ratio $\left(25^{\circ} \mathrm{C}\right)$ & $\%$ & $\geq 57$ & 67 & T0604 \\
\hline & Ductility $\left(10^{\circ} \mathrm{C}, 5 \mathrm{~cm} / \mathrm{min}\right)$ & $\mathrm{cm}$ & $\geq 8$ & 16.7 & T0605 \\
\hline
\end{tabular}

TABLE 2 | Properties of modifying agents.

\begin{tabular}{|c|c|}
\hline Modifying agent & Property and characteristic \\
\hline SBS & Molecular weight: 220-260 kD, block styrene content: 40.4\%, Shore A hardness: 82, white granular \\
\hline TR & $\begin{array}{l}\text { Molecular weight: } 650-2,600 \mathrm{kD} \text {, specific gravity: } 0.97 \text {, softening point: } 110^{\circ} \mathrm{C} \text {, glass transition temperature: } 84^{\circ} \mathrm{C} \text {, yellowish } \\
\text { viscous liquid or transparent brittle solid }\end{array}$ \\
\hline FEO & $\begin{array}{l}\text { Density }\left(20^{\circ} \mathrm{C}\right): 0.994 \mathrm{~g} / \mathrm{cm}^{3} \text {, flash point: } 251^{\circ} \mathrm{C} \text {, aniline point: } 30^{\circ} \mathrm{C} \text {, kinematic viscosity }\left(100^{\circ} \mathrm{C}\right): 35.36 \text {, aromatic } \\
\text { hydrocarbon content: } 82 \% \text {, dark green liquid }\end{array}$ \\
\hline SAW & Melting point: $115^{\circ} \mathrm{C}$, flash point: $290^{\circ} \mathrm{C}$, white or pale-yellow solid \\
\hline
\end{tabular}
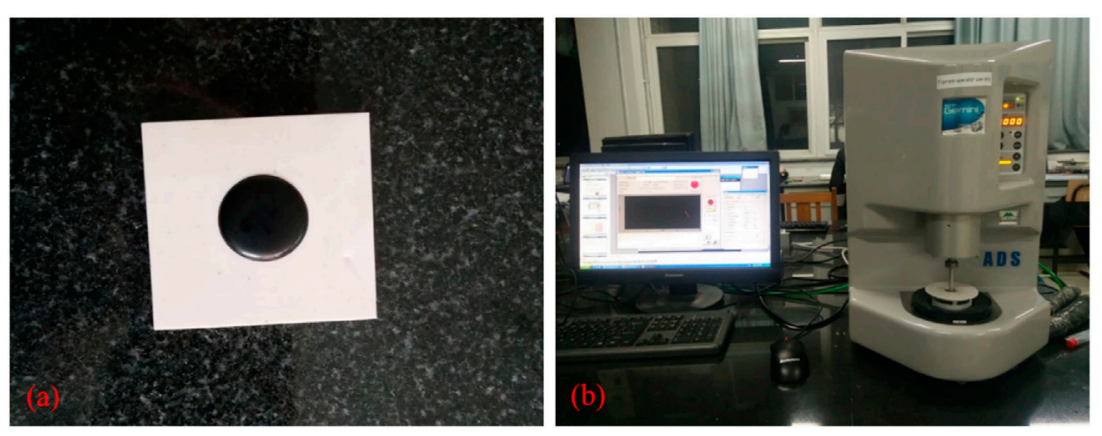

FIGURE 1 | (A) The preparation of specimens and (B) the DSR test.

washed with absolute ethyl alcohol. Cover slips were gently placed on the slide, which was placed in an oven at $135^{\circ} \mathrm{C}$ for $10 \mathrm{~min}$. After removing and cooling, a suitable multiple objective lens $(\times 400)$ was selected for microscopic observation.

\subsubsection{Dynamic Shear Rheometer Test}

Based on AASHTO T 315 (American Association of State Highway and Transportation Officials, 2012), dynamic shear rheometer (DSR) tests were conducted with a Gemini II ADS dynamic shear rheometer, selecting the strain-controlled mode with a frequency of $10 \mathrm{rad} / \mathrm{s}(1.59 \mathrm{~Hz})$. Five test temperatures from 64 to $88^{\circ} \mathrm{C}$ at increments of $6^{\circ} \mathrm{C}$ were applied in the Superpave grading system. The applied strain values, $\gamma$, for the original specimen, rolling thin film oven test (RTFO-aged) specimen, and pressure aging vessel test (PAV-aged) specimen were 12,10 , and $1 \%$, respectively. The original specimen and RTFO-aged specimen had a diameter of $25 \mathrm{~mm}$ and thickness of $1 \mathrm{~mm}$, while those of the PAV-aged specimen were 8 and $2 \mathrm{~mm}$, respectively. The test process was depicted in Figure 1.

\subsubsection{Bending Beam Rheometer Test}

Bending beam rheometer (BBR) tests were conducted using a CANNON bending beam rheometer to evaluate the lowtemperature rheological properties, in accordance with the procedures outlined in AASHTO T 313 (2016). When the loads were applied to asphalt beams $(125 \times 6.25 \times 12.5 \mathrm{~mm})$ during the detection process at test temperature of $-12,-18$ and $-24^{\circ} \mathrm{C}$, the deflection of the beams was recorded, and the deflection-time curve was obtained and analyzed using a software program to calculate creep stiffness $S$ and creep rate $m$. The test process was depicted in Figure 2.

\subsection{Preparation Scheme}

Composite modifier \# 1 was obtained by mixing SBS, SAW, and TR in a 2:1:2 ratio. The 90\# base asphalt, QRA, and composite modifier 

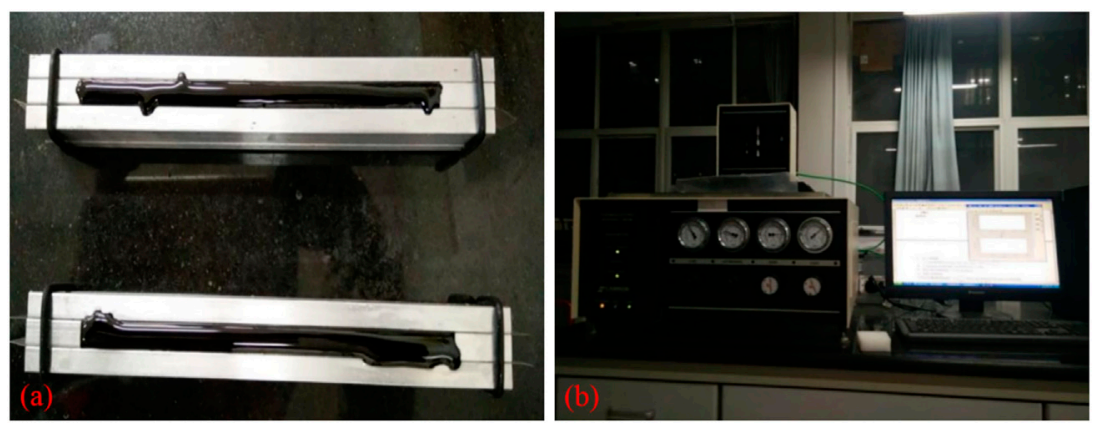

FIGURE 2 | (A) The preparation of specimens and (B) the BBR test.

\begin{tabular}{lcc}
$\begin{array}{l}\text { TABLE } 3 \text { | Scheme design of CNAMGA binder. } \\
\text { Factor specimen }\end{array}$ & A: QRA content (\%) & $\begin{array}{c}\text { B: Composite modifier } \\
\text { \#1 content (\%) }\end{array}$ \\
\hline 1 & $1(10.0)$ & $1(0)$ \\
2 & 1 & $2(3)$ \\
3 & 1 & $3(5)$ \\
4 & $2(12.5)$ & 1 \\
5 & 2 & 2 \\
6 & 2 & 3 \\
7 & $3(15.0)$ & 1 \\
8 & 3 & 2 \\
9 & 3 & 3
\end{tabular}

were used for specimen preparation. The standby base asphalt was heated to reach a flowing state in a constant-temperature oven at $135^{\circ} \mathrm{C}$. Then, an appropriate amount of base asphalt was heated to $160^{\circ} \mathrm{C}$ in the magnetic stirring electric heating mantle, and SBS was added bit by bit until all the SBS was added while stirring the binder for 40-50 min. Reference (Lu et al., 2009) showed that the 8\% content of QRA had no considerably adverse influence on low temperature performance. In view of the addition of modifier, 10, 12.5 and 15\% QRA for 90 \# base asphalt were determined. According to the different QRA contents, a small amount of asphalt was weighed, and small amounts of SAW, TR, and QRA were added until all the needed components were added while stirring for $1 \mathrm{~h}$. Next, the asphalt binder was stirred by a homomixer at a speed of 3,500 rpm for $40-50 \mathrm{~min}$, maintaining the mixing temperature at $160^{\circ} \mathrm{C}$. Finally, the CNAMGA binder specimens were prepared.

\section{RESULTS AND DISCUSSION}

\subsection{Fundamental Property Measurements 3.1.1 Orthogonal Test}

The specimens were prepared according to the preparation scheme for the CNAMGA binder. Factor A (the QRA content) had three levels $(10,12.5$, and $15.0 \%)$ and factor $B$ (the composite modifier \#1 content) had three levels $(0,3$, and $5 \%$ ), and various combinations were adopted to analyze the binder properties. The interaction between the factors was not considered, as the test arrangement shown in Table 3 indicates.

Asphalt penetration test $\left(25^{\circ} \mathrm{C}, 100 \mathrm{~g}, 5 \mathrm{~s}\right)$, ductility test $\left(10^{\circ} \mathrm{C}\right.$, $5 \mathrm{~cm} / \mathrm{min}$ ), softening point test (R\&B), and rolling thin film oven test (RTFOT) $\left(163^{\circ} \mathrm{C}\right.$, evaporation for $5 \mathrm{~h}$ ) were performed according to T0604-2011, T0605-2011, T0606-2011, and T0608-1993 of E20-2011 (Code of China, 2011), respectively. The results are shown in Figure 3.

As the results shown in Figure 3 indicate, when the QRA content is the same, the softening point increases and the mass loss decreases, the penetration increases and then decreases, and the ductility gradually decreases (except for specimen 6) with an increase in the modifier \#1 content. Referring to the technical requirements for modified hard asphalt binder in the Technical Guide on Design and Construction of Bridge Deck Paving of Highway Steel Box Girder, the specimen with the 10\% QRA content and less than 5\% modifier \#1 content does not meet the penetration requirements (1-4 mm). The specimen with $10 \%$ QRA and 5\% modifier \#1 or specimen with $15 \%$ QRA and any content of modifier \#1, does not meet the ductility requirement $(\geq 10 \mathrm{~mm})$. When the QRA content is $7.5 \%$ and the modifier \#1 content is less than $5 \%$, or the QRA content is $15 \%$ and the modifier \# 1 content is less than $3 \%$, the specimen doesn't meet the softening point requirement $\left(\geq 72^{\circ} \mathrm{C}\right)$. All the specimens meet the mass-loss requirement $(<0.5 \%)$. According to the above analysis, specimens with a $12.5 \%$ QRA content and 5\% modifier \# 1 content meet the all the index requirements.

\subsubsection{Variance Analysis}

Furthermore, given the test results and rules for different collocations of the CNAMGA binder in Figure 3, a variance analysis (Jamshidi et al., 2012) was adopted to investigate the influencing factors of different technical indexes. The results are presented in Table 4.

According to the one-tailed hypothesis test in mathematical statistics, with a confidence interval $(\alpha=0.05)$, when the factor degree of freedom is 2 and the error degree of freedom is 4 , it can be seen from the $F$ distribution table that the critical value is $F_{0.05}(2,4)$ $=6.9$. That is, there is a $95 \%$ certainty that $F \leq 6.9$ will appear, which can be judged to have no significant impact on the experimental index (acceptable region). If $F>6.9$ happens with only a $5 \%$ certainty, this indicates that the null hypothesis is not 


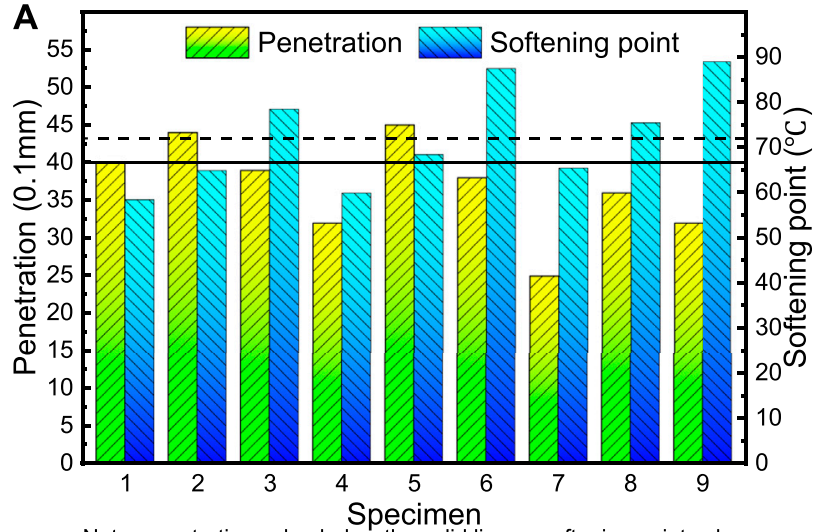

Note: penetration value below the solid line or softening point value above the dash line meet the reqiurements

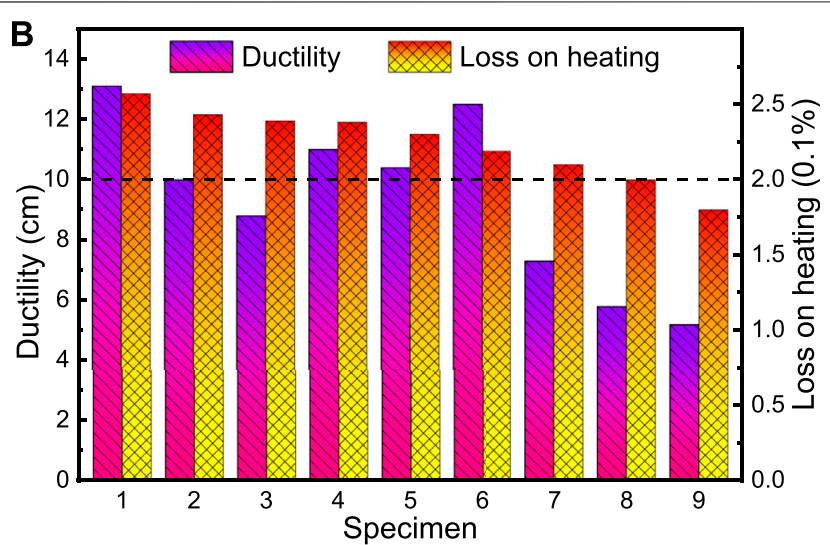

Note: ductility value above the dash line meet the reqiurements

FIGURE 3 | Results of (A) penetration test and softening point test, (B) ductility test and RTFOT.

TABLE 4 | Variance analysis results.

\begin{tabular}{|c|c|c|c|c|c|c|}
\hline Performance index & Variation source & $\begin{array}{l}\text { Degree of } \\
\text { freedom }\end{array}$ & Quadratic sum & Mean squares & $F$ Value & Critical value \\
\hline \multirow[t]{4}{*}{ Penetration } & $A$ & 2 & 160.89 & 80.44 & 11.05 & $F_{0.05}(2,4)=6.9$ \\
\hline & $\mathrm{B}$ & 2 & 131.56 & 65.78 & 9.04 & $F_{0.01}(2,4)=18.0$ \\
\hline & E (Error) & 4 & 29.11 & 7.28 & - & - \\
\hline & $\mathrm{T}$ (Total) & 8 & 321.56 & - & - & - \\
\hline \multirow[t]{4}{*}{ Softening point } & $A$ & 2 & 130.67 & 65.33 & 14.39 & $F_{0.05}(2,4)=6.9$ \\
\hline & $\mathrm{B}$ & 2 & 864.67 & 432.33 & 95.19 & $F_{0.01}(2,4)=18.0$ \\
\hline & $E$ & 4 & 18.17 & 4.54 & - & - \\
\hline & $\mathrm{T}$ & 8 & $1,013.50$ & - & - & - \\
\hline \multirow[t]{4}{*}{ Ductility } & $A$ & 2 & 48.04 & 24.02 & 10.86 & $F_{0.05}(2,4)=6.9$ \\
\hline & B & 2 & 5.68 & 2.84 & 1.28 & $F_{0.01}(2,4)=18.0$ \\
\hline & $E$ & 4 & 8.84 & 2.21 & - & - \\
\hline & $\mathrm{T}$ & 8 & 62.56 & - & - & - \\
\hline \multirow[t]{4}{*}{ Mass loss } & $A$ & 2 & 0.00381 & 0.00191 & 96.93 & $F_{0.05}(2,4)=6.9$ \\
\hline & $\mathrm{B}$ & 2 & 0.00075 & 0.00037 & 19.03 & $F_{0.01}(2,4)=18.0$ \\
\hline & $E$ & 4 & 0.00008 & 0.00002 & - & - \\
\hline & $\mathrm{T}$ & 8 & 0.00464 & - & - & - \\
\hline
\end{tabular}

valid, and that this factor has a significant impact on the experimental index (rejection region). The critical value is $F_{0.01}$ $(2,4)=18.0$, with a confidence interval $(\alpha=0.01)$. That is, there is a $99 \%$ certainty that $6.9<F<18.0$ will appear, which can be judged to have a significant impact on the experimental index (acceptable region). If $F>18.0$ occurs with only a $1 \%$ certainty, this indicates that the null hypothesis "this factor has a significant effect on the experimental index" is invalid, and this factor has a strongly significant impact on the experimental index (rejection region).

Note that because $6.9<F_{B}<F_{A}<18.0$ with regard to penetration, it can be considered that the QRA and modifier \# 1 contents have a significant impact on the penetration of the binder. From $F_{B}<6.9<F_{A}<18.0$ for the ductility, it can be seen that the QRA content has a significant effect, while the modifier $\# 1$ content has no significant effect on the ductility. The $6.9<F_{A}<$ $18.0<F_{B}$ for softening point indicates that the QRA content has a significant effect on the softening point, and the modifier \#1 content has a strongly significant effect on it. That $18.0<F_{B}<F_{A}$ for the mass loss illustrates that the QRA and modifier \#1 contents have a strongly significant impact on the mass loss.

The modifier \# 1 has a significant effect on the other indexes, but for the ductility, it is slightly less effective in improving the low-temperature performance of the asphalt. It is speculated that the modifier \#1 component may affect the compatibility and performance of the modified asphalt. The collocation of the modifier \#1 is adjusted to SBS: SAW: TR: FEO = 2: 2: $0.5: 0.5$, the TR content is reduced, and FEO, which can enhance the ductility at low temperature, is added. The objective of this new modifier (\#2) is to reduce the consistency, improve the compatibility between the modifier and asphalt, and improve the low-temperature performance of the binder.

\subsection{Fluorescent Microscope Test}

\subsubsection{Qualitative Analysis}

The microstructure of the modified asphalt significantly affects the properties of the modified asphalt. To confirm whether 

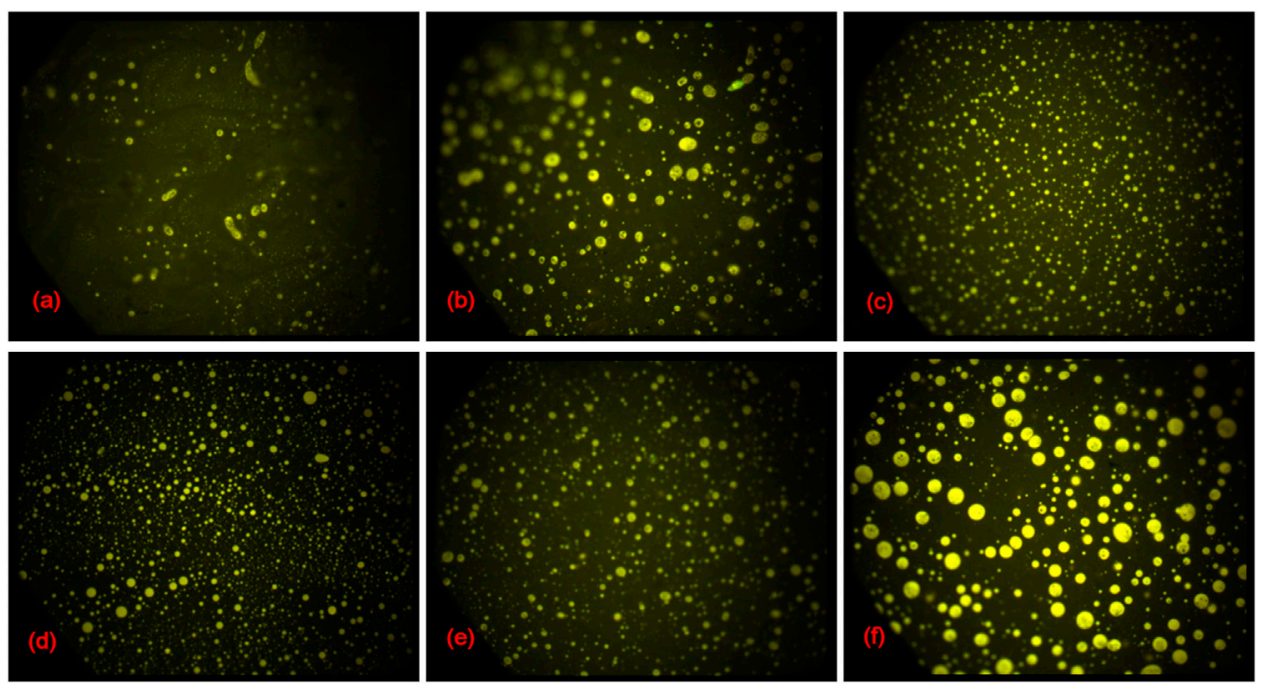

FIGURE 4 | Fluorescent microscope images, (A) specimen 2',

(B) specimen 3',

(C) specimen 5', (D)

) specimen 6',

(E) specimen 8', (F) specimen 9'.

modifier \#2 could live up to the expectations mentioned above, a fluorescent microscope is employed to observe and analyze the dispersibility and compatibility of the QRA and modifier in the binder. Six specimens (specimens 2', 3', 5', 6', 8', and 9') are remade with modifier \#2 according to the collocation in Table 3. They are then subjected to fluorescent microscope tests, and the results are shown in Figure 4.

Specimens presents different swollen polymer-rich phase from the vision of fluorescent microscope. In these pictures, the swollen polymer-rich phase has a bright yellow appearance and the dark region denotes the asphalt-rich phase. The QRA contents of specimens 2' and 3' are 10\%, those of specimens 5' and $6^{\prime}$ are $12.5 \%$, and those of specimen $8^{\prime}$ and $9^{\prime}$ are $15 \%$. The modifier \#2 contents of specimens 3', 6', and 9' are 5\%, and those of specimens 2', 5', and 8' are 3\%. The irregular shape of polymerrich phase in Figure 4A indicates the poor compatibility of the components in specimen 2'. Figure 4C shows that many polymer-rich phase in small size evenly distribute in specimen 5', implying better swelling comparing to specimen 2'. The distribution of polymers tends to sparse and inconspicuous in Figure 4E, indicating poor compatibility with higher content of QRA, the increasing addition of heavy fractions obstructs polymers swelled by light fractions. Compared with Figures 4A,B depicts the dispersed polymer-rich phase is proned to be spherical but distributes unevenly, implying modifier \#2 plays a certain role in compatibility. The compatibility shown in Figure 4D is slightly poorer than that seen in Figure 4C, which is not yet obvious. It is not difficult to see the shape of polymer-rich phase is large in size, indicating agglomeration with higher content of modifier \#2 and QRA from Figure $4 F$, and a potential phase separation may occur. The above phenomena prove that the modifier and QRA contents should coordinate with each other; mismatching will affect the dispersion of the different components in the binder. It can be concluded that the compatibility of the binders with the $12.5 \%$ QRA and $3 \%$ or $5 \%$ content of modifier \#2 is better.

\subsubsection{Quantitative Analysis}

The pictures in aforementioned statement are only partial visions under fluorescent microscope, which are representative, while sometimes a partial vision is hard to depict all-inclusive information. Extensive binarization treatment and mathematical statistics in fluorescent photomicrograph can present a more comprehensive result. Image-Pro Plus software (version 6.0), a powerful $2 \mathrm{D}$ and $3 \mathrm{D}$ image processing software, was employed to implement quantitative analysis. The area of the fluorescent part (that is, the pixels with gray values $\geq 175$ ) in the photomicrograph was analyzed. Taking specimens 5' and 6' as examples, Figure 5 presents the process of binarization treatment.

With binarization treatment, the sparse and uneven distribution of polymer-rich phase in specimen 5 ' tends to be more conspicuous than that of specimen 6'. In this way, the proportions of the fluorescence areas in the total areas of observation of different specimens could be quantitatively compared. Samples are observed multiple times using different fields of view, and mathematical statistics are used to determine the results, which are shown in Figure 6.

As shown in Figure 6, with the increase addition of modifier \#2 in the specimens with $10 \%$ content of QRA and specimens with $15 \%$ contents of QRA, the fluorescence spots area gradually decreases, while that of specimens with $12.5 \%$ content of QRA increases with the addition of modifier \#2. This proves that higher modifier and QRA contents do not yield better results, the role of modifier \#2 on the specimens with $12.5 \%$ content of QRA can be played to the better extent. Note that the fluorescence spots of the specimen with $12.5 \%$ QRA and 5\% modifier \#2 are the densest and the area proportion is the largest, as a result of the sufficient cross-linking and grafting reactions occurring in the binder. Therefore, the QRA and modifier contents should match each other, or the larger agglomeration or no fluorescent spots can be found under the sampling field. The statistical results show that the compatibility of the binder with the $12.5 \%$ QRA content and 

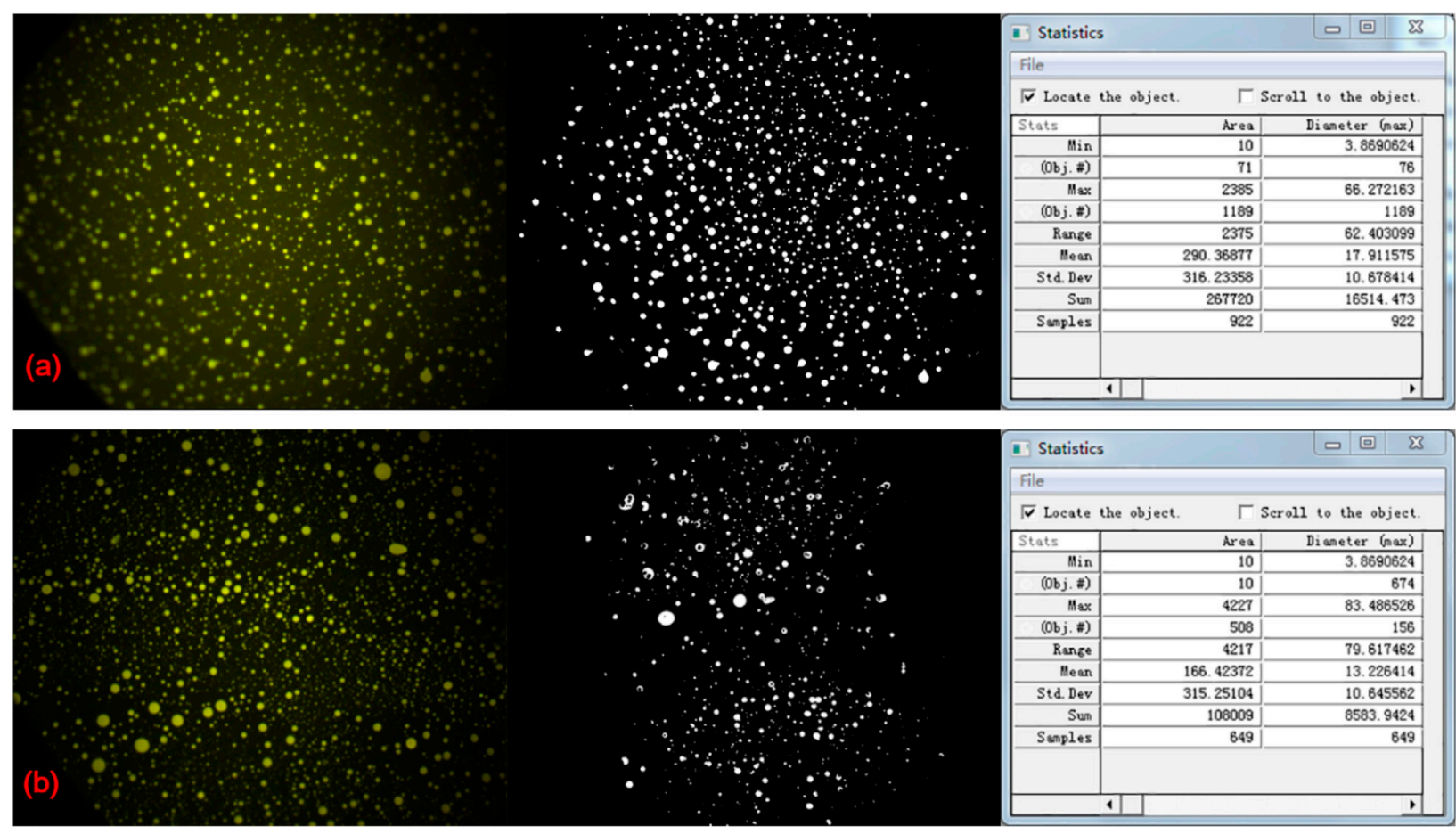

FIGURE 5 | Binarization treatment results of $\mathbf{( A )}$ specimen 5' and (B) specimen 6'.

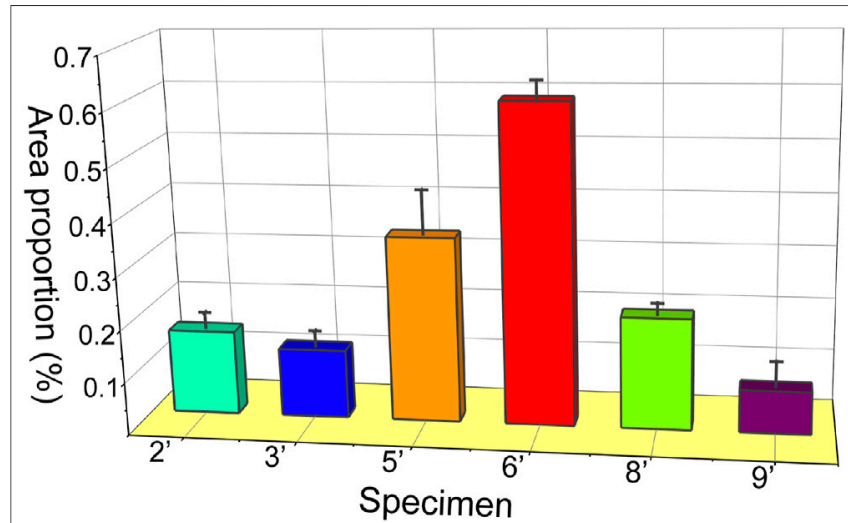

FIGURE 6 | Area ratio of modifier and QRA.

5\% modifier \#2 is superior, which could be considered as the main research object in next characterization of macroproperties.

\subsection{Superpave ${ }^{\mathrm{TM}}$ Asphalt Binder Tests 3.3.1 High-Temperature Performance}

The shear strength of asphalt concrete mainly depends on the bonding force caused by the interaction between the binder and aggregate and the internal friction angle caused by the intercalation of the aggregates in the asphalt mix. When the temperature goes up and shear stress increases, the asphalt binder viscosity decreases and the flow mobility increases, and the migration of binder to the pavement surface leads to a reduction on the internal friction angle of asphalt mix. The integrity and shear strength of the mix deteriorate, leading to pavement rutting and other pavement diseases (Al-Khateeb and Al-Akhras, 2011; Ali et al., 2017), therefore high-temperature performance is important for the serviceability of asphalt concrete. The rutting factor $G^{*} / \sin \delta$ can be considered to be a characterization parameter for the high-temperature performance. A larger value indicates a worse hightemperature fluidity, and a higher anti-rutting performance. Based on fluorescent microscope test, the compatibility of the binder with the $12.5 \%$ QRA content is regarded as superior, then specimens 4, 5', and 6' are subjected to DSR test, and the results are depicted in Figure 7.

As anticipated, complex modulus $G^{*}$ before and after aging decreases with the rising temperature, phase angle $\delta$ before and after aging increases with the rising temperature. At the same temperature, the larger $G^{\star}$ of the binder with modifier \#2 appears than that of binder without modifier \#2, indicating that binder with modifier \#2 has better deformation resistance, but the $G^{*}$ of binder with $3 \%$ modifier \#2 before aging has not much difference with that of binder without modifier \# 2 before aging. And the $\delta$ of modified binder is less than that of unmodified binder, the $\delta$ increases as the temperature increases for all samples. With the increasing dosage of modifier $\# 2$, the $\delta$ decreases at the same temperature, which indicates that the ratio of the elastic component in asphalt increases, the elastic recovery performance of asphalt has been improved. According to Superpave ${ }^{\mathrm{TM}}$, rutting factor $G^{*} / \sin \delta$ is limited to no less than 

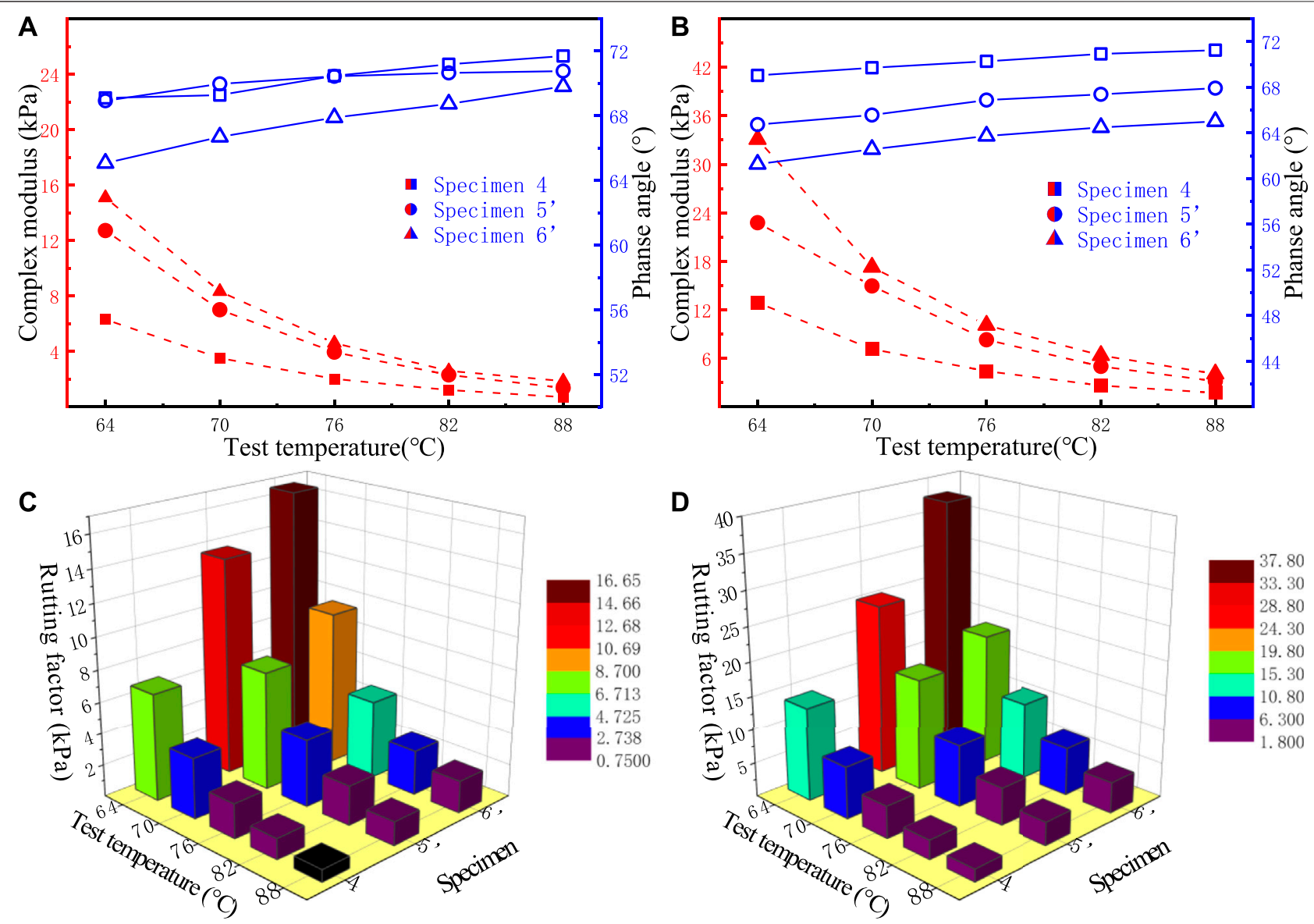

FIGURE 7 | Complex modules $G^{*}$ and phase angle $\delta$ (A) before RTFO-aged and (B) after RTFO-aged, rutting factor $G^{*} /$ sin $\delta$ (C) before RTFO-aged and (D) after RTFO-aged.

$1.0 \mathrm{kPa}$ for unaged binders or $2.2 \mathrm{kPa}$ for RTFO-aged binders (Jamshidi et al., 2012; Fazaeli et al., 2016; Kim et al., 2017b). As shown in Figures 7C,D, specimen 4 at $88^{\circ} \mathrm{C}$ before and after aging doesn't meet the requirements. Specimen 6', which has the largest $G^{\star} / \sin \delta$ value, has a superior high-temperature performance. The incorporation of the modifier changes the colloid structure of the asphalt, increasing the asphaltene content, which could harden the asphalt binder. Harder asphalt shows less conversion from elasticity to viscosity at high temperatures, enhancing the resistance to shear deformation at high temperatures. The composition of natural asphalt is similar to that of petroleum asphalt, but the content of hard components (resin and asphaltene) is higher in natural asphalt. Almost every large molecule of asphaltene contains the polar functional groups of carbon, hydrogen, oxygen, nitrogen, and sulfur, which can produce a strong adsorption force on the surface and improve the high-temperature performance of the asphalt. The performance grade (PG) at high or intermediate temperatures is increased by one level. From the above analysis, it can be seen that the high-temperature performance of the binder with $5 \%$ modifier $\# 2$ is better.

\subsubsection{Low-Temperature Performance}

Cracking not only destroys the continuity of pavement and reduces the driving quality, but also poses a water-induced distress concern, leading to the deterioration of the pavement bearing capacity and pavement damage. The low-temperature cracking resistance of asphalt pavement mainly depends on the tensile properties of the binder at low temperatures. In contrast to the high-temperature anti-rutting ability, the shrinkage cracking of asphalt pavement is usually caused by continuous aging, an increase in the stiffness modulus, and the gradual transformation of the low-temperature compliance into brittleness of the binder during its service life (You et al., 2011; Yao et al., 2012, Hui Yao et al., 2013). For comparison with the unadjusted modified binder, modifier \#2 is used to make specimens $5^{\prime}$ and 6 ' according to the collocation of specimens 5 and 6 with modifier \#1, and the test results are shown in Figure 8.

Reflecting the release rate of the shrinkage stress caused by the viscoelastic flow of the asphalt, a larger creep rate $m$-value indicates a better stress dissipation capacity for the asphalt and its crack resistance. Asphalt with a small creep stiffness (S) has less internal stress, better low-temperature compliance, 

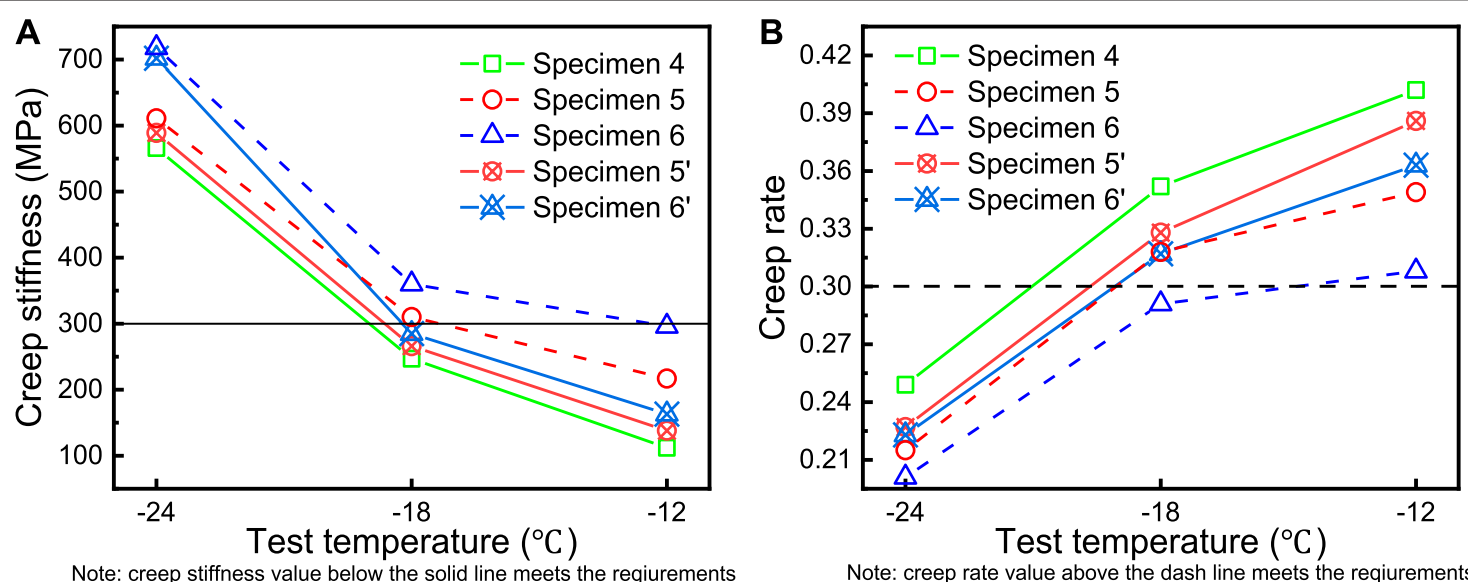

FIGURE 8 | (A) Creep stiffness $S$ and (B) creep rate $m$-value of different binder.

\begin{tabular}{|c|c|c|c|c|c|}
\hline Specimen & $\begin{array}{c}\text { PG of } \\
\text { original specimen } \\
\left({ }^{\circ} \mathrm{C}\right)\end{array}$ & $\begin{array}{c}\text { PG of } \\
\text { RFO-aged specimen } \\
\left({ }^{\circ} \mathrm{C}\right)\end{array}$ & $\begin{array}{c}\text { PG of } \\
\text { PAV-aged specimen } \\
\left({ }^{\circ} \mathrm{C}\right)\end{array}$ & $\begin{array}{l}\text { Low-temperature PG } \\
\left.\text { ( }{ }^{\circ} \mathrm{C}\right)\end{array}$ & $\begin{array}{l}\text { PG results } \\
\left({ }^{\circ} \mathrm{C}\right)\end{array}$ \\
\hline 4 & 82 & 82 & 25 & -18 & $82-18$ \\
\hline $5^{\prime}$ & 88 & 88 & 25 & -18 & $88-18$ \\
\hline $6^{\prime}$ & 88 & 88 & 25 & -18 & $88-18$ \\
\hline
\end{tabular}

and less chance of cracking at low temperatures. As shown in Figure 8, with the same QRA content, the $S$ value of the binderadded modifier is larger than that of the binder with no modifier, whereas the $m$-value of the binder with the modifier is smaller than that of the binder without the modifier. With an increase in the modifier content, $S$ increases, and the $m$-value decreases. It can be seen from this phenomenon that the binder will be hardened and the stress relief capacity will be reduced after the modifier is added, which will reduce the low-temperature performance of the binder to a certain extent. At the same time, note that the $S$ value of the binder with modifier \#2 is smaller and the $m$-value is larger than that of the binder with the same content of modifier \#1. The PG at low temperature is also improved by one level. Modifier \#2 plays a role in enhancing the lowtemperature performance of the binder, strongly proving that the adjusted modifier composition works effectively.

\subsubsection{Temperature Susceptibility}

Based on American Association of State Highway and Transportation Officials (2010) and American Association of State Highway and Transportation Officials (2007), the results of the PG determination of asphalt binder are summarized in Table 5.

Table 5 shows that the addition of modifier \#2 improved the PG at high or intermediate temperatures, and the influence of modifier \#2 on the PG at low-temperature is stable. Reflecting the sensitivity of the asphalt binder to temperature changes (Rasmussen et al., 2002; Al-Hadidy and Tan, 2009; Walters et al., 2014), the temperature susceptibility (TS) has an important influence on the pavement performance. One of technical indicators of the TS is the penetration.

The penetration index (PI) proposed by Pfeiffer (Pfeiffer and Doormaal, 1936) is calculated by the linear regression of the penetration test results in a temperature range of $15-30^{\circ} \mathrm{C}$. Obviously, the PI only reflects the TS at a normal temperature. It is meaningless for high or intermediate temperatures and low temperatures, which significantly affect the rheological properties of the binder. The $\mathrm{G}^{\star} / \sin \delta$ value with a change in temperature exactly indicates the TS of the asphalt at high or intermediate temperature ranges, and the $S$ value with a change in temperature exactly reflects the TS value of the asphalt in the low-temperature range. With temperature $\mathrm{T}$ as the independent variable, $\lg \left(\mathrm{G}^{*} / \sin \right)$ and $\lg S$ are considered as dependent variables, and can be defined as follows:

$$
\begin{gathered}
\lg \left(G^{*} / \sin \delta\right)=-A_{1} T+K_{1}, \\
\lg S=-A_{2} T+K_{2},
\end{gathered}
$$

where $A_{1}$ and $A_{2}$ are susceptibility factors, and $K_{1}$ and $K_{2}$ are regression constants.

Regression fitting was performed on the data of the three specimens, and the results are listed in Table 6.

As shown in Table 6, the fitting degree, $R^{2}$, values of all the equations were greater than 0.98 , indicating that both $\mathrm{G}^{*} / \sin \delta$ and $S$ were highly correlated with temperature T. By covering 
TABLE 6 | Linear equation regression analysis.

\begin{tabular}{|c|c|c|c|c|}
\hline \multirow[t]{2}{*}{ Specimen } & \multicolumn{2}{|c|}{ TS of high or intermediate temperatures } & \multicolumn{2}{|c|}{ TS of low temperature } \\
\hline & Regression equation & $R^{2}$ & Regression equation & $R^{2}$ \\
\hline 4 & $\lg \left(G^{*} / \sin \delta\right)=-0.0396 \mathrm{~T}+3.3552$ & 0.9993 & $\lg S=0.3518 T+1.6946$ & 0.9998 \\
\hline $5^{\prime}$ & $\lg \left(G^{*} / \sin \delta\right)=-0.2430 T+1.3650$ & 0.9991 & $\lg S=0.3151 T+1.8147$ & 0.9970 \\
\hline $6^{\prime}$ & $\lg \left(G^{*} / \sin \delta\right)=-0.2356 \mathrm{~T}+1.4308$ & 0.9905 & $\operatorname{lgS}=0.3308 T+1.8336$ & 0.9889 \\
\hline
\end{tabular}

the evaluated temperature, it is feasible for the binder to form an evaluation system for the TS. Generally speaking, a smaller absolute value for the susceptibility factor indicates a better resistance to TS. Among the three specimens, the TS at high or intermediate temperatures for specimen 4 is the best, while that at a low temperature is the worst. The TS at high or intermediate temperatures for specimen 5 ' is the worst, while that at a low temperature is the best. Combining the above factors, the collocation of specimen 6 ' could be identified as a better collocation with a superior comprehensive TS.

\section{CONCLUSION}

This study evaluated the compatibility of components at the microscale, as well as the thermal properties and rheological properties at the macroscale, of the CNAMGA binder. The following conclusions are drawn based on the results and discussion.

1) Variance analysis indicates the modifier \#1 has no significant impact on the improvement of ductility. Fluorescent microscope test implies that the compatibility of the binder with $12.5 \%$ QRA and 5\% modifier \#2 is superior.

2) The incorporation of the modifier obviously improves the high-temperature performance and reduces the lowtemperature performance of the binder to a certain extent. Whereas the low-temperature PG of the binder with modifier \#2 is superior compared with that of binder with modifier \#1.

3) The collocation of $12.5 \%$ QRA and $5 \%$ modifier \#2 could be identified as an optimal collocation with a superior hightemperature performance and comprehensive TS; it has a better performance in terms of the general and rheological properties. The performance of the mix prepared using the

\section{REFERENCES}

Al-Hadidy, A. I., and Yi-qiu, T. (2009). Mechanistic Approach for PolypropyleneModified Flexible Pavements. Mater. Des. 30, 1133-1140. doi:10.1016/j.matdes. 2008.06.021

Ali, S. I. A., Ismail, A., Karim, M. R., Yusoff, N. I. M., Al-Mansob, R. A., and Aburkaba, E. (2017). Performance Evaluation of Al2O3 Nanoparticle-Modified Asphalt Binder. Road Mater. Pavement Des. 18, 1251-1268. doi:10.1080/ 14680629.2016 .1208621

Al-Khateeb, G. G., and Al-Akhras, N. M. (2011). Properties of Portland CementModified Asphalt Binder Using Superpave Tests. Constr. Build. Mater. 25, 926-932. doi:10.1016/j.conbuildmat.2010.06.091
CNAMGA binder remains to be verified through relevant tests.

\section{DATA AVAILABILITY STATEMENT}

The original contributions presented in the study are included in the article/Supplementary Material, further inquiries can be directed to the corresponding authors.

\section{AUTHOR CONTRIBUTIONS}

Conceptualization, TL and QJ; methodology, TL and PJ; software, YD; writing-original draft preparation, $\mathrm{QJ}$ and PJ; writing-review and editing, QJ and HS; visualization, ZY; supervision, QJ; project administration, NS; funding acquisition, HS and YD. All authors have read and agreed to the published version of the manuscript.

\section{FUNDING}

This research was funded by the China Postdoctoral Science Foundation (Grant Nos 2019M662442), the National Natural Science Foundation of China (No. 51803109), and the Young Talent of Lifting engineering for Science and Technology in Shandong (SDAST 2021qt01).

\section{ACKNOWLEDGMENTS}

The authors wish to express their sincere gratitude for the kind assistance of Shandong province key laboratory of Shandong Jiaotong University and Shandong University.

American Association of State Highway and Transportation Officials (2010). AASHTO M 320, Standard Specification for Performance-Graded Asphalt Binder. Washington DC.

American Association of State Highway and Transportation Officials (2007). AASHTO PP 42, Standard Practice for Determination of Low-Temperature Performance Grade (PG) of Asphalt Binders. Washington DC.

American Association of State Highway and Transportation Officials (2016). AASHTO T313, Standard Method of Test for Determining the Flexural Creep Stiffnessof Asphalt Binder Using the Bending BeamRheometer. Washington DC: BBR.

American Association of State Highway and Transportation Officials (2012). AASHTO T 315, Standard Method of Test for Determining the Rheological Propertiesof Asphalt Binder Using a Dynamic ShearRheometer. Washington DC: DSR. 
Artamendi, I., Allen, B., Allpress, C., Phillips, P., and Wingrove, C. (2017). "Resurfacing of the Queen Elizabeth II Bridge: Binder Selection and evaluation," in Railways and Airfields (BCRRA 2017), Athens, Greece, 28-30 June, 2017. doi:10.1201/ 9781315100333-325

Bai, T., Hu, Z.-a., Hu, X., Liu, Y., Fuentes, L., and Walubita, L. F. (2020). Rejuvenation of Short-Term Aged Asphalt-Binder Using Waste Engine Oil. Can. J. Civ. Eng. 47, 822-832. doi:10.1139/cjce-2019-0268

Cavalli, M. C., Griffa, M., Bressi, S., Partl, M. N., Tebaldi, G., and Poulikakos, L. D. (2016). Multiscale Imaging and Characterization of the Effect of Mixing Temperature on Asphalt concrete Containing Recycled Components. J. Microsc. 264, 22-33. doi:10.1111/jmi.12412

Chen, J. S., Liao, M. C., and Huang, C. C. (2011a). "Evaluation of Guss Asphalt Applied to Steel Deck Surfacing," in 1st Congress of the Transportation and Development Institute of ASCE, Chicago, IL, 13-16 March, 2011. doi:10.1061/ 41167(398) 45

Chen, J. S., Liao, M.-C., Huang, C.-C., and Wang, C.-H. (2011b). Fundamental Characterization of Engineering Properties of Gussasphalt Mixtures. J. Mater. Civ. Eng. 23, 1719-1726. doi:10.1061/(ASCE)MT.1943-5533.0000339

Chen, Q., Wang, C., Sun, X., Cao, Y., Guo, T., and Chen, J. (2019). Evaluation and Prediction for Effect of Conductive Gussasphalt Mixture on Corrosion of Steel Bridge Deck. Constr. Build. Mater. 228, 116837. doi:10.1016/j.conbuildmat. 2019.116837

Code of China (2011). JTG E20-2011, Standard Test Methods of Bitumen and Bituminous Mixtures for Highway Engineering. Beijing: China Communications Press.

Das, P. K., Baaj, H., Tighe, S., and Kringos, N. (2016). Atomic Force Microscopy to Investigate Asphalt Binders: a State-Of-The-Art Review. Road Mater. Pavement Des. 17, 693-718. doi:10.1080/14680629.2015.1114012

Du, S. (2014). Interaction Mechanism of Cement and Asphalt Emulsion in Asphalt Emulsion Mixtures. Mater. Struct. 47, 1149-1159. doi:10.1617/s11527-013-0118-1

Fazaeli, H., Amini, A. A., Moghadas Nejad, F., and Behbahani, H. (2016). Rheological Properties of Bitumen Modified with a Combination of $\mathrm{Ft}$ Paraffin Wax (Sasobit) and Other Additives. J. Civil Eng. Manage. 22, 135-145. doi:10.3846/13923730.2014.897977

Gao, B., Wang, M., and Hao, Z. H. (2015). Bending Behavior of Glass Fiber Grid Reinforced Gussasphalt. Appl. Mech. Mater. 744-746, 754-757. doi:10.4028/ www.scientific.net/amm.744-746.754

Grover Allen, R. G., Little, D. N., Bhasin, A., and Glover, C. J. (2014). The Effects of Chemical Composition on Asphalt Microstructure and Their Association to Pavement Performance. Int. J. Pavement Eng. 15, 9-22. doi:10.1080/10298436. 2013.836192

Huang, W., Sun, M., and Qin, Y. (2019). The Influence of the Warm-Mixed Agent on the Performance of Gussasphalt after Superheated Aging, IOP Conf. Ser. Earth Environ. Sci. 304, 052128. doi:10.1088/1755-1315/304/5/052128

Jamshidi, A., Hamzah, M. O., and Aman, M. Y. (2012). Effects of Sasobit Content on the Rheological Characteristics of Unaged and Aged Asphalt Binders at High and Intermediate Temperatures. Mat. Res. 15, 628-638. doi:10.1590/S151614392012005000083

Jia, X., Huang, B., Chen, S., and Shi, D. (2016). Comparative Investigation into Field Performance of Steel Bridge Deck Asphalt Overlay Systems. KSCE J. Civ Eng. 20, 2755-2764. doi:10.1007/s12205-016-0259-1

Jin, L., Qian, Z., and Zheng, Y. (2014). High Temperature Performance and Evaluation index of Gussasphalt Mortar Based on DMA Method. Dongnan Daxue Xuebao (Ziran Kexue Ban)/J. Southeast Univ. (Nat. Sci. Ed.) 44, 1062-1067. doi:10.3969/j.issn.1001-0505.2014.05.033

Ke, Z., Mingzhi, S., and Yunjie, Q. (2019). Study on the Rheological Properties of Gussasphalt after Superheat Aging, IOP Conf. Ser. Earth Environ. Sci. 233, 032002. doi:10.1088/1755-1315/233/3/032002

Kim, H. H., Lee, M. S., Lee, M. S., and Lee, S. J. (2016). Identification of the Microstructural Components of Crumb Rubber Modified Asphalt Binder (CRMA) and the Feasibility of Using Environmental Scanning Electron Microscopy (ESEM) Coupled with Energy Dispersive X-Ray Spectroscopy (EDX). Int. J. Highw. Eng. 18, 41-50. doi:10.7855/ijhe.2016.18.6.041

Kim, H. H., Mazumder, M., and Lee, S. J. (2017a). Micromorphology and Rheology of Warm Binders Depending on Aging. J. Mater. Civil Eng. 29, 04017226. doi:10.1061/(ASCE)MT.1943-5533.0002082

Kim, H. H., Mazumder, M., Torres, A., Lee, S.-J., and Lee, M.-S. (2017b). Characterization of CRM Binders with Wax Additives Using an Atomic
Force Microscopy (AFM) and an Optical Microscopy. Adv. Civ. Eng. Matls. 6, 20160071. doi:10.1520/acem20160071

Liu, X., Zou, X., Yang, X., and Zhang, Z. (2018). Effect of Material Composition on Antistripping Performance of SBS Modified Asphalt Mixture under Dry and Wet Conditions. J. Adhes. Sci. Technol. 32, 1503-1516. doi:10.1080/01694243. 2018.1426973

Liu, K. (2019). Research on Construction Fluidity of Gussasphalt Mixture. Wuhan Ligong Daxue Xuebao (Jiaotong Kexue Yu Gongcheng Ban)/J. Wuhan Univ. Technol. (Transport. Sci. Eng.) 43, 341-345. doi:10.3963/j.issn.2095-3844.2019. 02.032

Lu, Z., He, Z., Yu, Q., and Gang, H. (2009). Influence of Rock Asphalt Modified Asphalt on Asphalt Rheological Property. Chongqing Jiaotong Univ. (Nat. Sci. Version) 28, 543-547. doi:10.3969/j.issn.1674-0696.2009.03.18

Luo, R., Shi, C., Fan, X., and Feng, G. (2018a). Research on Permanent Deformation of Gussasphalt Mixture under Dynamic Penetration. Huazhong Keji Daxue Xuebao (Ziran Kexue Ban)/J. Huazhong Univ. Sci. Technol. (Nat. Sci. Ed.) 46, 13-16. doi:10.13245/j.hust.180703

Luo, S., Qian, Z., Yang, X., and Lu, Q. (2018). Laboratory Evaluation of Double-Layered Pavement Structures for Long-Span Steel Bridge Decks. J. Mater. Civil Eng. 30, 04018111. doi:10.1061/(ASCE)MT.1943-5533. 0002291

Mazumder, M., Ahmed, R., Wajahat Ali, A., and Lee, S.-J. (2018). SEM and ESEM Techniques Used for Analysis of Asphalt Binder and Mixture: A State of the Art Review. Construction Building Mater. 186, 313-329. doi:10.1016/j.conbuildmat. 2018.07.126

Pfeiffer, J. P., and Doormaal, P. M. (1936). The Rheological Properties of Asphaltic Bitumens. J. Inst. Pet. 22, 414-440.

Pouget, S., Sauzéat, C., Di Benedetto, H., and Olard, F. (2010). Numerical Simulation of the Five-point Bending Test Designed to Study Bituminous Wearing Courses on Orthotropic Steel Bridge. Mater. Struct. 43, 319-330. doi:10.1617/s11527-009-9491-1

Qian, J., Wang, Q., Wu, W., and Zhang, H. (2013). Fatigue Performance of Gussasphalt concrete Made from Modified AH-70\# Asphalt. Mater. Des. (1980-2015) 52, 686-692. doi:10.1016/j.matdes.2013.06.009

Qiu, Y., An, S., Rahman, A., and Ai, C. (2019). Evaluation and Optimization of Bridge Deck waterproof Bonding System Using Multi-Objective Grey Target Decision Method. Road Mater. Pavement Des. 21, 1844-1858. doi:10.1080/ 14680629.2019.1568288

Rasmussen, R. O., Lytton, R. L., and Chang, G. K. (2002). Method to Predict Temperature Susceptibility of an Asphalt Binder. J. Mater. Civil Eng. 14, 246-252. doi:10.1061/(asce)0899-1561(2002)14:3(246)

Shadkam, H. R., Dadsetan, S., Tadayon, M., Sanchez, L. F. M., and Zakeri, J. A. (2017). An Investigation of the Effects of limestone Powder and Viscosity Modifying Agent in Durability Related Parameters of Self-Consolidating concrete (SCC). Constr. Build. Mater. 156, 152-160. doi:10.1016/j. conbuildmat.2017.08.165

Singh, D., and Sawant, D. (2016). Understanding Effects of RAP on Rheological Performance and Chemical Composition of SBS Modified Binder Using Series of Laboratory Tests. Int. J. Pavement Res. Technol. 9, 178-189. doi:10.1016/j. ijprt.2016.06.002

Walters, R. C., Fini, E. H., and Abu-Lebdeh, T. (2014). Enhancing Asphalt Rheological Behavior and Aging Susceptibility Using Bio-Char and Nanoclay. Am. J. Eng. Appl. Sci. 7, 66-76. doi:10.3844/ajeassp.2014.66.76

Wang, H., and Li, G. (2015). Study of Factors Influencing Gussasphalt Mixture Performance. Constr. Build. Mater. 101, 193-200. doi:10.1016/j.conbuildmat. 2015.10.082

Wang, M., Zhang, H., Zhu, M., Hao, Z., and Xue, X. (2011). "Research on Structure and Properties of Embedded Gussasphalt," in Proceedings of the GeoHunan International Conference, Hunan, China, 9-11 June, 2011.

Wang, C., Chen, Q., Fu, H., and Chen, J. (2018a). Heat Conduction Effect of Steel Bridge Deck with Conductive Gussasphalt concrete Pavement. Constr. Build. Mater. 172, 422-432. doi:10.1016/j.conbuildmat.2018.03.161

Wang, C., Yang, X., Li, Q., Guo, T., and Jiang, T. (2018b). Preparation and Performance of Conductive Gussasphalt concrete. Transportmetrica A: Transport Sci. 15, 55-70. doi:10.1080/23249935.2018.1449913

Wang, M., Fang, M. S., Zhang, G. J., Li, J., and Wen, F. (2019). Design of Asphalt Pavement Structure on Steel Deck of Hong Kong-Zhuhai-Macao Bridge. Bridge Constr. 49, 69-74. doi:10.3969/j.issn.1003-4722.2019.04.013 
Wu, W. J., He, Z. Y., Hao, Z. H., and Wang, M. (2013). "Differences in Fatigue Behavior Among the Gussasphalt, SMA and AC," in Advanced Materials Research. doi:10.4028/www.scientific.net/amr.723.276

Xie, F., Zhang, D., Zhou, A., Ji, B., and Chen, L. (2017). On the Viscoelastic Parameters of Gussasphalt Mixture Based on Modified Burgers Model: Deviation and Experimental Verification. Adv. Mater. Sci. Eng. 2017, 1-11. doi:10.1155/2017/4324765

Xin, C., Lu, Q., Ai, C., Rahman, A., and Qiu, Y. (2017). Optimization of Hard Modified Asphalt Formula for Gussasphalt Based on Uniform Experimental Design. Constr. Build. Mater. 136, 556-564. doi:10.1016/j.conbuildmat.2017. 01.068

Yang, J., Zhu, X., Yuan, Y., and Li, L. (2020). Effects of Aging on Micromechanical Properties of Asphalt Binder Using AFM. J. Mater. Civil Eng. 32, 04020081. doi:10.1061/(ASCE)MT.1943-5533.0003030

Yao, H., You, Z., Li, L., Lee, C. H., Wingard, D., Yap, Y. K., et al. (2013). Rheological Properties and Chemical Bonding of Asphalt Modified with Nanosilica. J. Mater. Civil Eng. 25, 1619-1630. doi:10.1061/(ASCE)MT.1943-5533.0000690

Yao, B., Cheng, G., Wang, X., and Cheng, C. (2013). Characterization of the Stiffness of Asphalt Surfacing Materials on Orthotropic Steel Bridge Decks Using Dynamic Modulus Test and Flexural Beam Test. Construction Building Mater. 44, 200-206. doi:10.1016/j.conbuildmat.2013.03.037

Yao, H., and You, Z. (2016). Effectiveness of Micro- and Nanomaterials in Asphalt Mixtures through Dynamic Modulus and Rutting Tests. J. Nanomater. 2016, 1-14. doi:10.1155/2016/2645250

Yao, H., You, Z., Li, L., Shi, X., Goh, S. W., Mills-Beale, J., et al. (2012). Performance of Asphalt Binder Blended with Non-modified and Polymer-Modified Nanoclay. Construction Building Mater. 35, 159-170. doi:10.1016/j. conbuildmat.2012.02.056

You, Z., Mills-Beale, J., Fini, E., Goh, S. W., and Colbert, B. (2011). Evaluation of Low-Temperature Binder Properties of Warm-Mix Asphalt, Extracted and Recovered Rap and Ras, and Bioasphalt. J. Mater. Civil Eng. 23, 1569-1574. doi:10.1061/(ASCE)MT.1943-5533.0000295

Yu, X., Burnham, N. A., and Tao, M. (2015). Surface Microstructure of Bitumen Characterized by Atomic Force Microscopy. Adv. Colloid Interf. Sci. 218, 17-33. doi:10.1016/j.cis.2015.01.003
Zhang, H., Qian, J. S., Wu, W. J., Zhang, F., and Hao, Z. H. (2010). Fatigue Life Analysis of Gussasphalt concrete Based on Energy Method. Tumu Jianzhu Yu Huanjing Gongcheng/Journal Civil, Architectural Environ. Eng. 32, 135-140.

Zhang, H., Zhang, G., Han, F., Zhang, Z., and Lv, W. (2018). A Lab Study to Develop a Bridge Deck Pavement Using Bisphenol A Unsaturated Polyester Resin Modified Asphalt Mixture. Construction Building Mater. 159, 83-98. doi:10.1016/j.conbuildmat.2017.10.126

Zhao, Y., Ni, F., Zhou, L., and Jiang, J. (2020). Performance Evaluation of LongSpan Suspension Bridge Pavement Based on Long-Term Maintenance Data. J. Mater. Civil Eng. 32, 04019363. doi:10.1061/(ASCE)MT.1943-5533.0003019

Zou, G., Xu, X., Li, J., Yu, H., Wang, C., and Sun, J. (2020). The Effects of Bituminous Binder on the Performance of Gussasphalt Concrete for Bridge Deck Pavement. Materials 13, 364. doi:10.3390/ma13020364

Conflict of Interest: TL, ZY, and NS were employed by Shandong Hi-speed Construction Management Group Co., Ltd.

The remaining authors declare that the research was conducted in the absence of any commercial or financial relationships that could be construed as a potential conflict of interest.

Publisher's Note: All claims expressed in this article are solely those of the authors and do not necessarily represent those of their affiliated organizations, or those of the publisher, the editors and the reviewers. Any product that may be evaluated in this article, or claim that may be made by its manufacturer, is not guaranteed or endorsed by the publisher.

Copyright (C) 2022 Li, Jin, Jiang, Sun, Ding, Yan and Shi. This is an open-access article distributed under the terms of the Creative Commons Attribution License (CC $B Y)$. The use, distribution or reproduction in other forums is permitted, provided the original author(s) and the copyright owner(s) are credited and that the original publication in this journal is cited, in accordance with accepted academic practice. No use, distribution or reproduction is permitted which does not comply with these terms. 